\title{
Characterization and Electrochromic Properties of Poly(2,3,5,6-Tetrafluoroaniline): Progress Towards a Transparent Conducting Polymer
}

\author{
Lavinia Astratine \\ University of Limerick \\ Edmond Magner \\ University of Limerick \\ John Cassidy \\ Technological University Dublin, john.cassidy@tudublin.ie
}

See next page for additional authors

Follow this and additional works at: https://arrow.tudublin.ie/aegart

Part of the Chemistry Commons

\section{Recommended Citation}

Astratine, L., Magner, E., Cassidy, J. \& Betts, A. (2012) Characterization and Electrochromic Properties of Poly(2,3,5,6-Tetrafluoroaniline): Progress Towards a Transparent Conducting Polymer. Electrochimica Acta, Vol. 74, 15 July, 2012, pp.117-12. doi:10.1016/j.electacta.2012.04.032

This Article is brought to you for free and open access by the Applied Electrochemistry Group at ARROW@TU Dublin. It has been accepted for inclusion in Articles by an authorized administrator of ARROW@TU Dublin. For more information, please contact arrow.admin@tudublin.ie, aisling.coyne@tudublin.ie, gerard.connolly@tudublin.ie.

Funder: INSPIRE:joint University of Limerick and Technological University Dublin Common Interest Group and the Programme for Research in Third Level Institutions . 


\section{Authors}

Lavinia Astratine, Edmond Magner, John Cassidy, and Tony Betts

This article is available at ARROW@TU Dublin: https://arrow.tudublin.ie/aegart/2 


\title{
Characterization and electrochromic properties of $\operatorname{poly}(2,3,5,6$-tetrafluoroaniline): Progress towards a transparent conducting polymer
}

\author{
Lavinia Astratine $^{\mathrm{a}}$, Edmond Magner ${ }^{\mathrm{a}, *}$, John Cassidy $^{\mathrm{b}, *}$, Anthony Betts $^{\mathrm{c}, *}$ \\ a Materials Surface and Science Institute E Department of Chemical and Environmental Sciences, University of Limerick, Limerick, Ireland \\ b School of Chemical and Pharmaceutical Sciences, Dublin Institute of Technology, Kevin St, Dublin 8, Ireland \\ c Applied Electrochemistry Group, Dublin Institute of Technology, Focas Institute, Camden Row, Dublin 8, Ireland
}

\section{A R T I C L E I N F O}

\section{Article history:}

Received 26 October 2011

Received in revised form 5 April 2012

Accepted 6 April 2012

Available online $\mathrm{xxx}$

\section{Keywords:}

Poly(2,3,5,6-tetrafluoroaniline)

Transparent conducting polymer

Cyclic voltammetry

Spectroelectrochemistry

\begin{abstract}
A B S T R A C T
Electrochromic films of poly(2,3,5,6-tetrafluoroaniline) (PTFA) were formed on ITO substrates from aqueous solutions utilising perchloric acid $\left(\mathrm{HClO}_{4}\right)$ as dopant. Electrochemical and spectroscopic characterization of PTFA films was performed in background electrolyte and in solutions with the addition of tetrahydrofuran. When the PTFA film was removed from its growth medium, a significant decrease in the faradaic current was observed. The faradaic response increased on addition of tetrahydrofuran which facilitates ion movement through the polymer matrix. PTFA films deposited on ITO substrate were orange and light orange in the oxidized and reduced forms, respectively. The films were ca. $25 \mathrm{~nm}$ in thickness. In aqueous solution the films showed a porous structure with a non-uniform distribution of pore diameters. In the presence of tetrahydrofuran a less porous structure was observed.
\end{abstract}

(c) 2012 Elsevier Ltd. All rights reserved.

\section{Introduction}

Since their discovery, conducting polymers (CPs) [1] which are also known as electroactive polymers have been extensively investigated for electrochromic applications $[2,3]$. The energy gap between the valence and conduction bands of the polymer provides a first estimation of the electronic excitation energy which can be measured spectroscopically. The spectroscopic signal depends not only on the energy of the electronic transition but also on the efficiency of the transition [4]. The colour change between doped and undoped forms of the polymer depends on the magnitude of the band gap of the undoped polymer. For example oxidative p-doping shifts the optical absorption band towards the lower energy part of the spectrum [4].

Polypyrrole (PPy), polythiophene (PTh) and polyaniline (PANI) [5] are formed during anodic oxidation and are amongst the most extensively studied electroactive polymers [6]. Polyaniline (PANI) and its derivatives are of particular interest due to their stability [7]. Polyaniline films can be formed during electrochemical deposition using potentiostatic, potentiodynamic and galvanostatic methods [8]. The polymer possesses three oxidation states: leucoemeraldine (neutral), emeraldine (polaron) and pernigraniline (bipolaron). The

\footnotetext{
* Corresponding authors. Tel.: +353061 234168; fax: +353061203529.

E-mail addresses: lavinia.astratine@ul.ie (L. Astratine), edmond.magner@ul.ie (E. Magner), john.cassidy@dit.ie (J. Cassidy), anthony.betts@dit.ie (A. Betts).
}

leucoemeraldine form represents the fully reduced form, emeraldine is half-oxidized and pernigraniline is the fully oxidized state of polyaniline. The electrical conductivity of polyaniline based materials can be closely controlled over a wide range. The most common, protonated emeraldine, has a high conductivity of $100 \mathrm{~S} \mathrm{~cm}^{-1}$, similar to that of a semiconductor [7].

Polymerization of aniline monomers containing fluorine has been performed both chemically and electrochemically; however the properties of these polymers have not been fully characterised. Monofluoro-substituted anilines [9] have been synthesised from acidic solutions using a chemical oxidation process and characterised by a range of spectroscopic methods. Chemically synthesised poly(2-fluoroaniline) and poly(3-fluoroaniline) showed similar absorption spectra to that of the 2-fluoroaniline monomer. With the 4-fluoroaniline monomer, dehalogenation occurred during polymerization, with fluorine being displaced to yield a more favourable head-to-tail polymer with the resultant UV-Vis spectrum being identical to that of polyaniline [9]. The solubilities of polyfluoroanilines in organic solvents were improved in comparison to polyaniline [9]. Poly(tetrafluroaniline) was used as a substrate for a bacterial fuel cell [8], but was not examined as an electrochromic material. Electrochemical polymerization of 2,3,5,6-tetrafluoroaniline was carried out in aqueous-acidic solutions under potentiostatic control. Poly(2,3,5,6-tetrafluoroaniline) modified platinum electrodes showed improved stability compared to poly(2-fluoroaniline) when they were exposed to microbially aggressive conditions such as sewage or sewage sludge 
for long time periods [8]. Poly(2,3,5,6-tetrafluoroaniline) was the most resistive material towards microbial degradation and prevented poisoning of platinum by metabolic by-products [8].

The electrochemical behaviour of 2-fluoroaniline, 3fluoroaniline and 4-fluoroaniline electrodeposited on platinum electrode were examined in aqueous acidic and organic media using $\mathrm{NaClO}_{4}$ as electrolyte [10]. During electrochemical oxidation, poly (2-, 3- and 4-) fluoroanilines were successfully deposited on the surface of the electrode but the transition from the emeraldine to the pernigraniline form was not observed, due to the fluorine electron withdrawing group [10].

A significant number of reports have described the development of transparent conducting polymers and in particular the use of chemically synthesised poly(3,4-ethylenedioxythiophene) (PEDOT) with polystyrenesulphonate (PSS) as counter ion to form conductive films. For example, dispersions of films of PEDOT: PSS in DMSO with single walled carbon nanotubes have been sprayed on polyethyleneterephthalate (PET) [11]. The resultant films had a resistance of $118 \Omega /$ sq and $90 \%$ transmittance over the wavelength range $400-800 \mathrm{~nm}$. In situ polymerization of EDOT with 2,3dichloro-5,6-dicyanobenzoquinone (DDQ) (molar ratio of 1:1.33) yielded films with $80 \%$ transmittance over the range $300-700 \mathrm{~nm}$ [12]. Similar films were formed with a sulfonated derivative of polythiophene [13]. No electrochromic studies have been described for these transparent polymers. However a polypyrrole/polythiophene co-polymer had a uniform absorbance between $400 \mathrm{~nm}$ and $800 \mathrm{~nm}$ while reduced [14] only upon oxidation a strong absorbance at $600 \mathrm{~nm}$ resulted. Another system of aniline/thiophene co-polymer displayed a relatively constant change in absorbance with potential, but had a slight absorbance maximum at $800 \mathrm{~nm}$ [15].

To our knowledge, there have been no electrochromic studies of PTFA. This paper describes the formation of PTFA thin films on a conducting ITO substrate by successive potential cycling in acidic solutions. The films obtained were characterised by electrochemical and spectroscopic techniques. PTFA polymer showed an improved electrochemical response when tetrahydrofuran was added to the solution. The UV-Vis spectra displayed a single broad absorbance peak over the visible spectrum which can be attributed to a neutral to polaron electronic transition. The effects of different electrolytes on the properties of the polymer are described.

\section{Experimental}

2,3,5,6-Tetrafluoroaniline and tetrahydrofuran were purchased from Sigma-Aldrich and perchloric acid (60\%) from BDH Laboratory Supplies, UK. In order to avoid degradation, 2,3,5,6tetrafluoroaniline was stored under dry conditions in the dark. Cyclic voltammetry was employed to electropolymerize PTFA films onto conducting indium tin oxide glass (ITO). A three electrode cell was used with an ITO glass slide (Solaronix, Switzerland), platinum coil ( $0.5 \mathrm{~mm}$, Alfa-Aesar, $\mathrm{UK})$ and $\mathrm{Ag} / \mathrm{AgCl}(3 \mathrm{M} \mathrm{KCl})(\mathrm{CH}$ Instruments Inc., UK) as working, counter and reference electrodes, respectively. All potentials are reported vs $\mathrm{Ag} / \mathrm{AgCl}(3 \mathrm{M}$ $\mathrm{KCl})$. The dimensions of the ITO electrodes were $0.5 \mathrm{~cm} \times 2.5 \mathrm{~cm}$. The ITO sheet resistance was $18 \Omega$ /sq. The electrodes were carefully cleaned by successive ultrasonication in deionized water, followed by acetone and then deionized water to ensure removal of all traces of acetone and finally dried in air prior to use. Water with a resistivity of $18 \mathrm{M} \Omega \mathrm{cm}$ (Elgastat Maxima) was used for all studies. Solutions ( $10 \mathrm{ml}$ volume) containing $50 \mathrm{mM}$ monomer (2,3,5,6-tetrafluoroaniline) and $2 \mathrm{M} \mathrm{HClO}_{4}$ were prepared in deionized water. Monomer solutions were deoxygenated with nitrogen for $5 \mathrm{~min}$ prior to use. All solutions were freshly prepared for each experiment. Electrochemical experiments were performed using a CHI 620 model potentiostat. UV-Vis absorption spectra

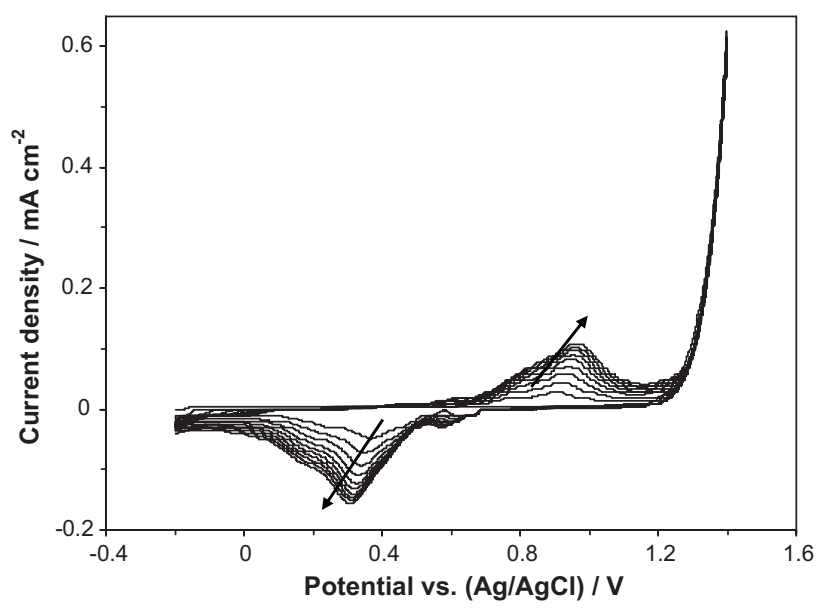

Fig. 1. Cyclic voltammograms of PTFA film deposited on ITO glass from an aqueous solution containing $50 \mathrm{mM}$ TFA and $2 \mathrm{M} \mathrm{HClO}_{4}$. Scan rate of $40 \mathrm{mV} \mathrm{s}^{-1}$. Number of cycles: 15.

were recorded on a Shimadzu 1800 UV-Vis spectrophotometer. The colouration efficiency was measured by chronoamperometry, by switching the potential between $0 \mathrm{~V}$ and $1.2 \mathrm{~V}$. SEM images were obtained using a Hitachi SU-70 scanning electron microscope.

\section{Results and discussion}

\subsection{Cyclic voltammetry of PTFA films}

PTFA films were deposited onto ITO electrodes under potentiodynamic conditions from aqueous media with the addition of perchloric acid $\left(\mathrm{HClO}_{4}\right)$ as dopant. Cyclic voltammograms of TFA in aqueous solution (Fig. 1) indicated that the optimal conditions for electropolymerization were obtained over the potential range $-0.2 \mathrm{~V}$ to $+1.4 \mathrm{~V}$ at a constant scan rate of $40 \mathrm{mV} \mathrm{s}^{-1}$. Monomer oxidation commences at a potential of ca. $1.2 \mathrm{~V}$. Thin films were formed since thicker films possess an increased resistance which compromises the conductivity of the polymers. On successive scans, the peak currents at ca. $0.9 \mathrm{~V}$ increased slightly, indicating that a conductive polymeric film was formed on the electrode. As the number of cycles increased, the potential for oxidation of the polymer increased to more positive values and the potential for reduction to more negative values. Also on the reduction scan, two peaks were observed at $0.6 \mathrm{~V}$ and $0.3 \mathrm{~V}$. The appearance of the small peak at ca. $0.3 \mathrm{~V}$ depends on the upper potential limit used. On increasing the upper potential to $1.6 \mathrm{~V}$, the reduction peak potential at $0.3 \mathrm{~V}$ increased to $0.4 \mathrm{~V}$.

Electropolymerization of tetrafluoroaniline on ITO is proposed to occur via the same mechanism (Scheme 1) described for the polymerization of aniline. As evident from the first anodic scan, it is the electron-withdrawing effect of fluorine which gives rise to the increase in potential required for monomer oxidation. On continuous sweeping the peak potential separation increases indicating that the polymer oxidation/reduction process is becoming more difficult, which is likely due to the increased hydrophobicity of the film. Note that PTFA films were also deposited on fluorine doped $\mathrm{SnO}_{2}$, however a very poor electrochemical response was obtained and all studies were thus performed with ITO electrodes.

\subsection{Electrochemical characterization of the PTFA films}

PTFA polymer characterization was performed in different solutions: with background electrolyte alone, with the addition of monomer, or with the addition of tetrahydrofuran. The nature of the supporting electrolyte used during electrochemical cycling of 


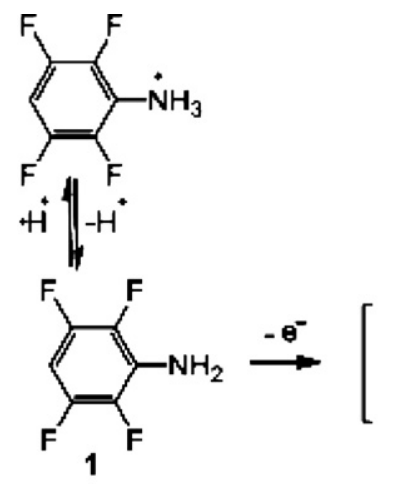<smiles>NC1C(F)C(F)C(CCNc2c(F)c(F)cc(F)c2F)C(F)C1F</smiles>

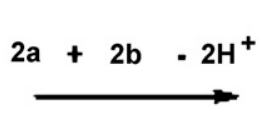<smiles>Nc1c(F)c(F)c(Nc2c(F)c(F)cc(F)c2F)c(F)c1F</smiles><smiles>N=C1C(F)=C(F)C(=Nc2c(F)c(F)cc(F)c2F)C(F)=C1F</smiles><smiles>CC(C)C</smiles>

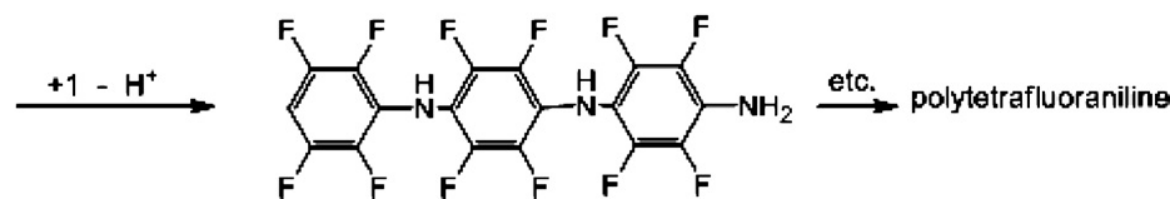

Scheme 1. Proposed mechanism for polymerization of 2,3,5,6-tetrafluoroaniline.

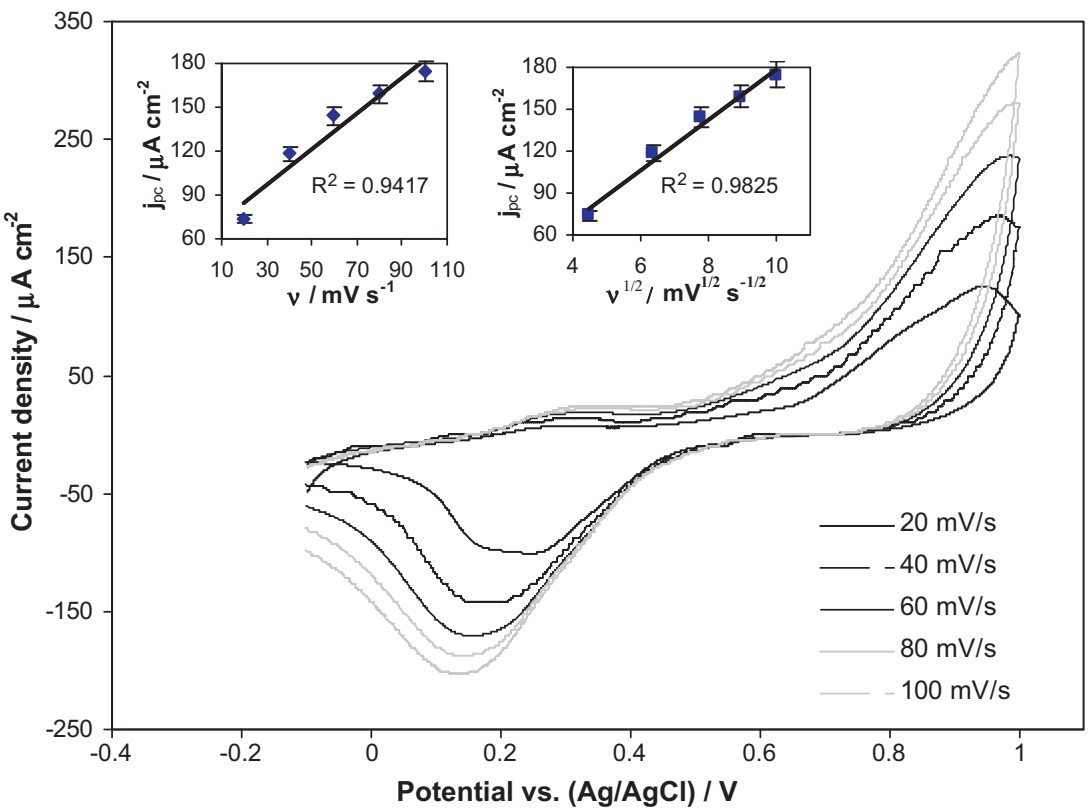

Fig. 2. Cyclic voltammograms of PTFA film as a function of scan rate in a solution containing $50 \mathrm{mM} \mathrm{TFA}$ and $2 \mathrm{M} \mathrm{HClO}_{4}$. Insert graphs show plots of cathodic peak current versus $v$ and $v^{1 / 2}$. 


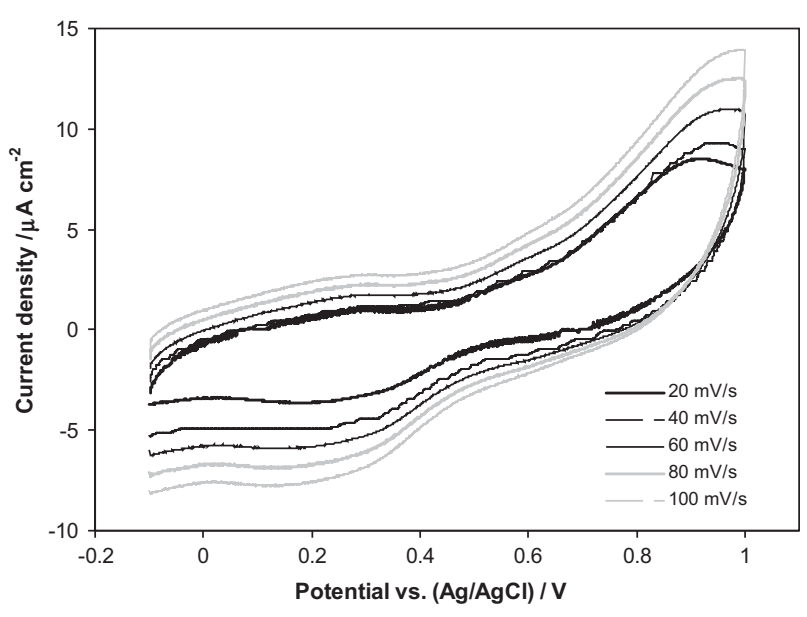

Fig. 3. Cyclic voltammograms of PTFA film deposited on ITO as a function of scan rate in $2 \mathrm{M} \mathrm{HClO}_{4}$ aqueous solution.

PTFA has considerable influence on the properties of the polymer [16]. Voltammetric characterization of the PTFA films deposited on ITO glass was performed in the same solution used for film formation, over the potential range $-0.2 \mathrm{~V}$ and $1.0 \mathrm{~V}$ to avoid further monomer oxidation. The polymer was characterised in the presence of the monomer as the voltammetric response deteriorated in solutions containing only background electrolyte. The resultant cyclic voltammograms (Fig. 2) exhibited a similar response to that obtained during polymer deposition (Fig. 1). On the cathodic sweep, the peak currents were well defined, while upon oxidation the peak potentials shifted towards more positive values with increasing scan rate. The ratio of $j_{\mathrm{pa}}$ to $j_{\mathrm{pc}}$ should be close to one for an ideal thin layer system, but the rate of the oxidation process was slow and $j_{\text {pa }}$ could not be measured (Fig. 2). Cyclic voltammograms of films in the presence of monomer displayed an increase in the oxidation peak potential with increasing scan rate and also a slight shift in the peak potentials with increased scan rate. The inset in Fig. 2 shows that the polymer does not display thin layer behaviour, instead displaying behaviour corresponding to bulk diffusion. The linear plot of $j_{\mathrm{p}}$ vs $v^{1 / 2}$ can be ascribed to slow ion movement arising from the hydrophobic nature of the film [17].

On transferring the electrode to monomer-free solution containing $2 \mathrm{M} \mathrm{HClO}_{4}$ a dramatic change in response was observed (Fig. 3). The anodic peak currents were significantly reduced and the peaks broadened, possibly indicating that ion incorporation during the polymer oxidation/reduction process was slow. It is obvious that the absence of the monomer caused a decrease in the peak currents which are three times lower in $2 \mathrm{M} \mathrm{HClO}_{4}$ compared to those in the monomer solution. The electrochemical response of PTFA in background electrolyte alone is in contrast with other conducting polymers such as polypyrrole and polythiophene which have large capacitive currents [18,19]. In general, for conducting polymers the conductivity correlates with the capacitance of the film [20]. In aqueous $2 \mathrm{M} \mathrm{HClO}_{4}$ the decrease in current densities is due to a loss in conductivity of the film.

The addition of tetrahydrofuran to the aqueous $2 \mathrm{M} \mathrm{HClO}_{4}$ solution changes the electrochemical behaviour of the polymer (Fig. 4). Tetrahydrofuran (THF) is a polar aprotic solvent characterised by a low dielectric constant of 7.5 [21]. In the presence of THF, the peak currents increase, possibly indicating that the hydrophobic polymeric layer is more open and allows counter ions to move in and out more readily during the redox cycle. In contrast to the data in Fig. 2 , the reduction peak current increases linearly with scan rate, indicative of thin layer behaviour [22] (Fig. 4). Increasing the amount of THF resulted in increases in the peak current which are associated

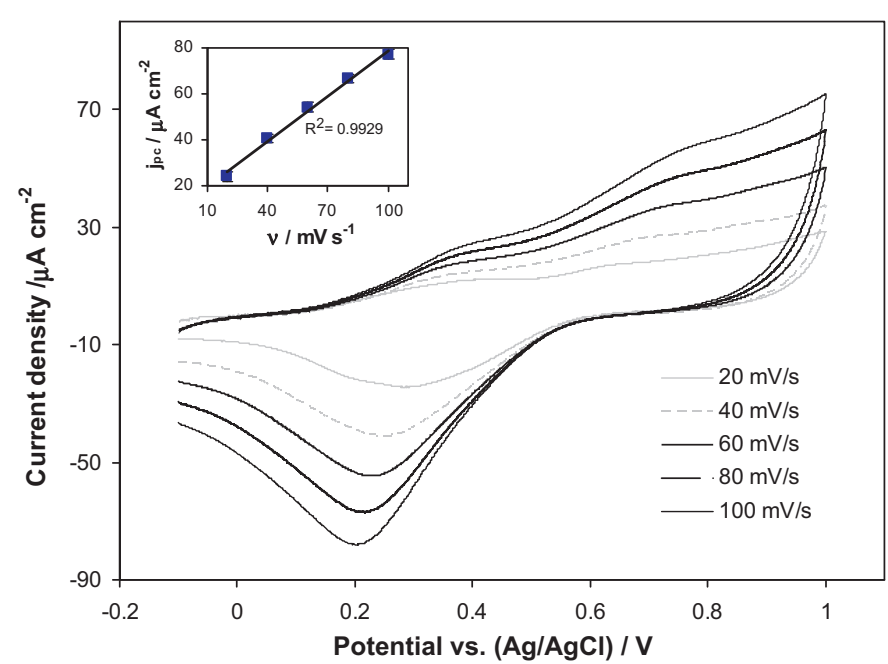

Fig. 4. Cyclic voltammograms of a PTFA film on ITO in $2 \mathrm{M} \mathrm{HClO}_{4}$ aqueous solution with $16.66 \%$ THF.

with increased ion mobility into and out of the film during the redox cycle [23] (Fig. 5).

\subsection{Spectroelectrochemistry of the PTFA polymer}

Spectroelectrochemical analysis was performed in the presence and absence of THF to investigate the optical properties of the polymer. There is a uniform increase in absorbance as a function of potential over the wavelength range $420 \mathrm{~nm}$ to $730 \mathrm{~nm}$ (Fig. 6). In addition the spectral band is particularly broad, covering this entire wavelength range. This is reflected in the change from a delicate orange to a much deeper orange colour as the potential is increased [12].

The changes in absorbance (Fig. 6) due to the electronic transition corresponding to a neutral to a polaron state, similar to that seen for monofluorinated anilines [10]. The isosbestic point related to a simple two stage system is not present as the neutral polymer electronic transition is at lower wavelengths below $420 \mathrm{~nm}$. The band-gap $\left(\pi-\pi^{*}\right)$ transition for aniline is generally observed around and sometimes below $300 \mathrm{~nm}$ which represents a limitation for electro-optical applications [24]. Compared to spectra of polyaniline, the range of wavelengths associated with the transition in PTFA is very wide, which is due to the presence of fluorine electron withdrawing group. The PTFA films did not exhibit large

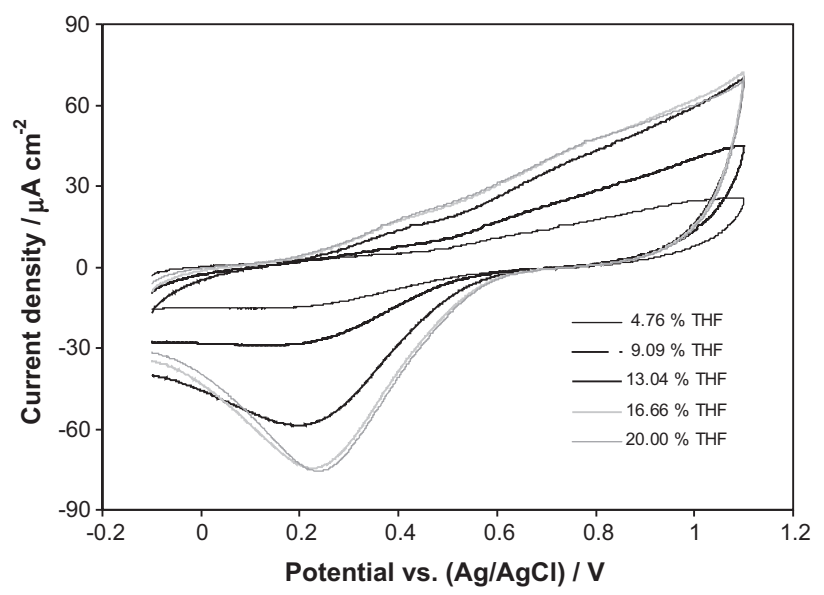

Fig. 5. Cyclic voltammograms of a PTFA film cycled at $100 \mathrm{mV} \mathrm{s}^{-1}$ in $2 \mathrm{M} \mathrm{HClO}_{4}$ aqueous electrolyte while increasing the tetrahydrofuran concentration. 


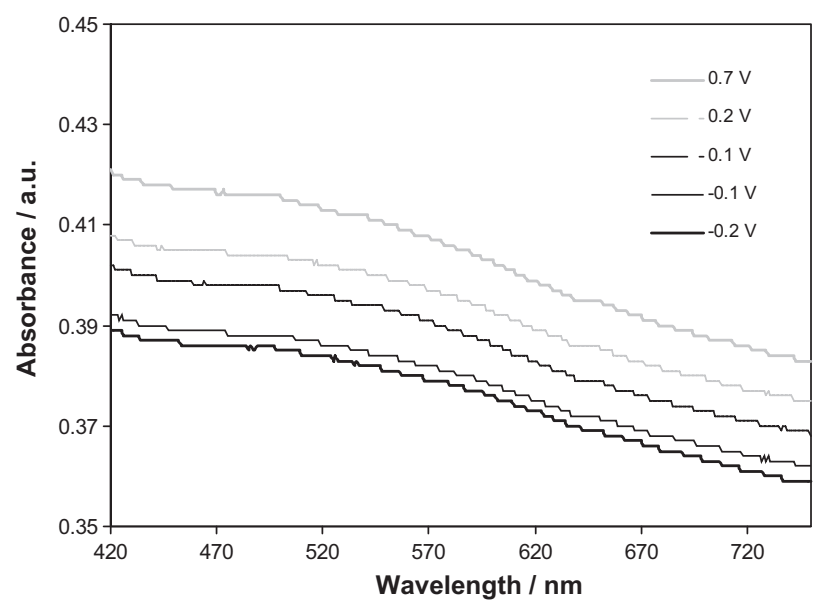

Fig. 6. UV-Vis spectra of PTFA film in $2 \mathrm{M} \mathrm{HClO}_{4}$ aqueous solution as a function of applied potential.

absorbance changes on oxidation/reduction, even on addition of THF.

\subsection{Electrochromic switch}

The response time measured upon switching the polymer film between its neutral and oxidized states was monitored at $450 \mathrm{~nm}$ (Fig. 7). The polymer thickness was controlled by adjusting the number of potential cycles. The film used for this study was a thin film as the charge passed through during deposition was $13.6 \times 10^{-4} \mathrm{C} \mathrm{cm}^{-2}$. The colouration efficiency (CE) is an important characteristic for electrochromic materials and corresponds to the amount of charge injected in the polymer as a function of the change in optical density. The coulombic efficiency $(\eta)$ is related to the performance of the electrochromic device and is defined as the ratio between the change in optical density $(\Delta \mathrm{OD})$ and the injected/ejected charge per unit area of the electrode at a specific wavelength $\left(\lambda_{\max }\right)[23]$. Absorbance variations with time under a step potential oscillating between the oxidized and reduced states of the polymer at $\lambda_{\max }$ in the visible range are essential for an electrochromic material. The absorbance change as the polymer is cycled between oxidized and reduced state provides details of the optical contrast and electro-optical stability [25].

The polymer film on ITO does not display dramatic colour variations, changing from orange in the oxidized form to a more bleached orange colour in the reduced form. Consequently, the colouration

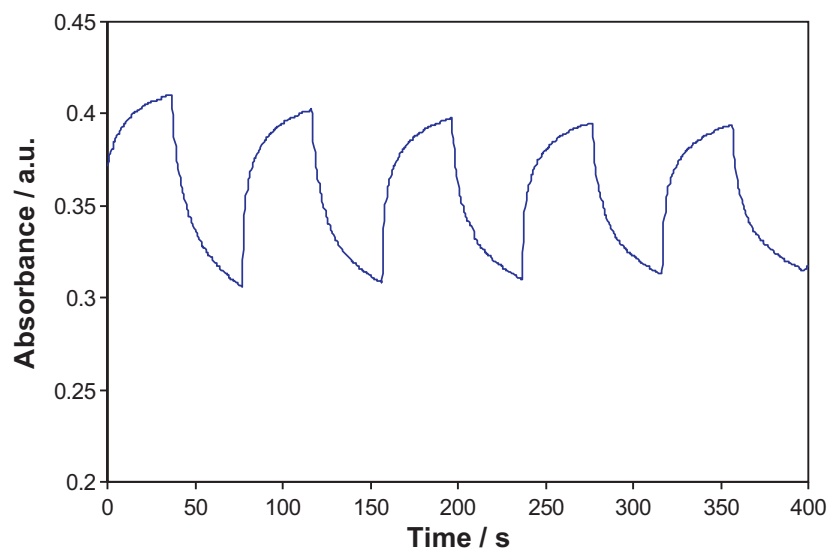

Fig. 7. Plot of absorbance $(\lambda=450 \mathrm{~nm})$ vs time of a PTFA film as the potential was switched between $0 \mathrm{~V}$ and $1.2 \mathrm{~V}$. The solution contained $2 \mathrm{M} \mathrm{HClO}_{4}$ and $50 \mathrm{mM}$ monomer. Switching interval of $40 \mathrm{~s}$. efficiency had a value of $36.6 \mathrm{~cm}^{2} \mathrm{C}^{-1}$ at $450 \mathrm{~nm}$, which is low when compared to other electrochromic materials. A dual electrochromic system containing poly(3,4-ethylenedioxythiophene) and poly(3methylthiophene) had a high colouration efficiency of $460 \mathrm{~cm}^{2} \mathrm{C}^{-1}$ at $665 \mathrm{~nm}$ [26] where the colours ranged between deep red and deep blue.

The colour changes recorded at $450 \mathrm{~nm}$ wavelength require longer times, due to the increasing difficulty of inserting ions into the polymer matrix. The hydrophobic nature of PTFA polymer makes the injection of ions on oxidation more difficult in aqueous media, while upon reduction they are more easily released. As stated in the literature the polymer colour depends on the polymer

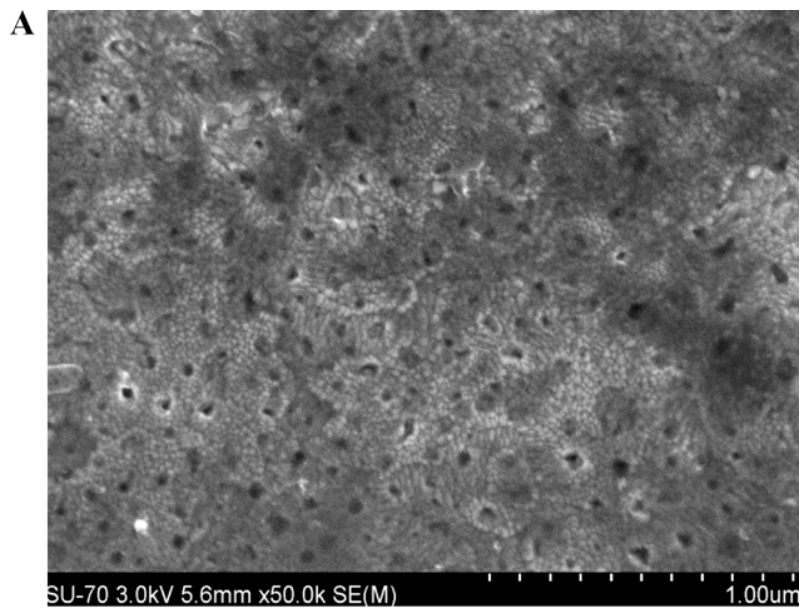

B

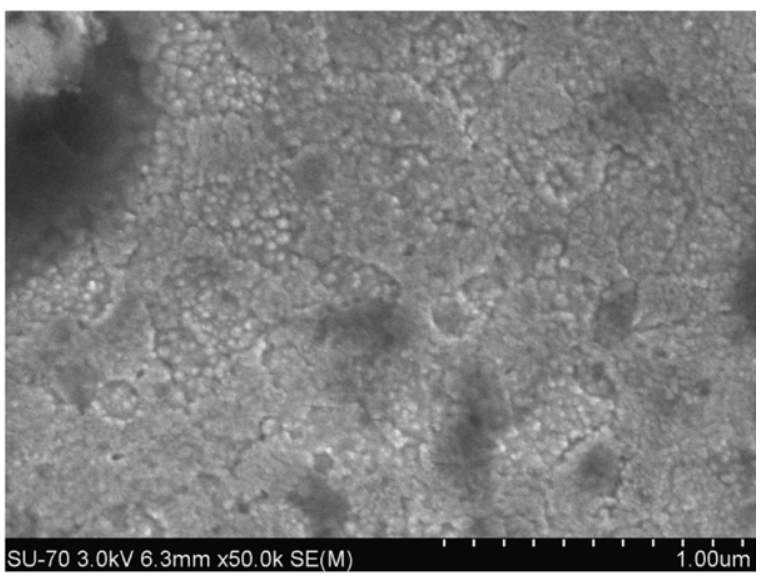

C

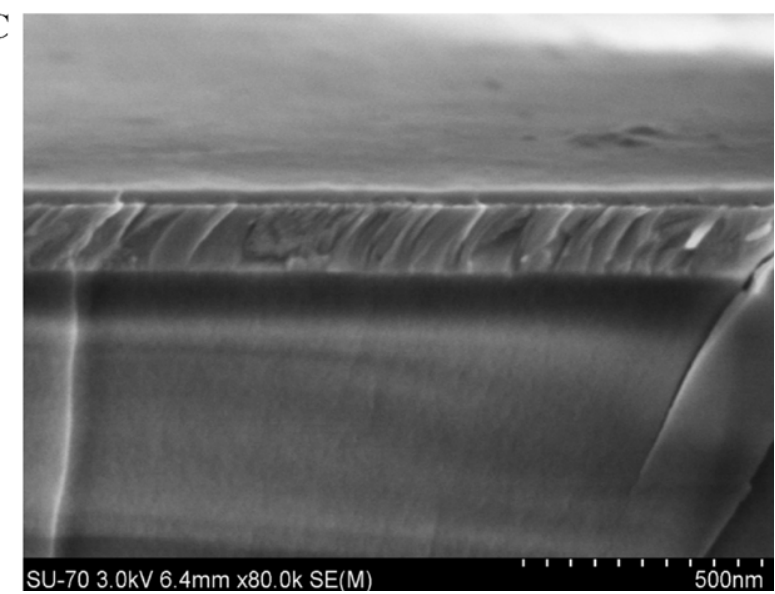

Fig. 8. (A) SEM image of PTFA polymer from aqueous solutions; (B) SEM image of PTFA polymer from solutions with tetrahydrofuran (20\%); (C) SEM cross-section image of PTFA film run in aqueous solution. 
chain-length. An increase in resistivity was observed from cyclic voltammetry (Fig. 1) and UV-Vis spectra (Fig. 7). The changes in absorbance spectra seen at $450 \mathrm{~nm}$ are very small and the rate of the oxidation-reduction process is very slow as the system required over $40 \mathrm{~s}$ to switch between different oxidation states. Ideally a fast switching time of less than a few seconds is required for most electrochromic device applications [27].

Slow transients have been reported elsewhere in the literature for a polypyrrole/polythiophene system ( $>20 \mathrm{~s})$ [14] and for Tempo/viologen electrochromic devices (>50 s) [28,29].

\subsection{Morphology investigation}

SEM was used to study the detailed surface morphology of two polymer films in $2 \mathrm{M} \mathrm{HClO}_{4}$ aqueous solution with and without THF deposited ITO substrate. Both films were removed from solution and allowed to dry without any post treatment. Fig. 8A shows the morphology of PTFA films obtained in aqueous solution containing $2 \mathrm{M} \mathrm{HClO}_{4}$ without THF deposited on ITO substrate. PTFA films had an uneven highly porous structure (Fig. 8A) with pore diameters of ca. $50 \mathrm{~nm}$. On addition of THF (Fig. 8B) the film morphology is less porous than for the PTFA in aqueous solutions. It is interesting to notice the changes of polymer structure in the presence of $20 \%$ THF which shows less numerous pores. In general a less porous structure (Fig. 8B) may affect the diffusion of ions into and out of the entire bulk film decreasing the electroactivity [23]. This contradicts the electrochemical study of PTFA/20\% THF (Fig. 4) which indicates the presence of a more electroactive layer compared to PTFA/aqueous solution (Fig. 3). However, SEM images were obtained after the films were removed from solution and completely dried and may not reflect the structure of the films in solution. The presence of $20 \%$ THF created films with reduced numbers of pore but with increased pore size which facilitates the insertion/expulsion of $\mathrm{ClO}_{4}{ }^{-}$into the polymer $[23,30]$. The thickness of the polymeric film was $25 \mathrm{~nm}$ (Fig. 8C), in reasonable agreement with the value of $15.2 \mathrm{~nm}$ calculated from the charge passed during polymer oxidation $\left(Q=13.6 \times 10^{-4} \mathrm{C} \mathrm{cm}^{-2}\right)$.

\section{Conclusions}

PTFA films were successfully deposited on a ITO substrate and characterised by electrochemical and spectroscopic methods. Spectroelectrochemical measurements showed a broad absorbance peak over the visible region of the spectrum with an increase in absorbance across the spectrum as the potential was increased. The addition of THF improved the electrochemical response of PTFA films in aqueous solutions. In $2 \mathrm{M} \mathrm{HClO}_{4}$ aqueous solution the films showed a significant decrease in the faradaic response. An increase in the peak currents was observed on addition of THF. The presence of fluorine substituents to form PTFA did not introduce extra stability, as ion movement was hindered and the voltammetric response was more sluggish than that of polyaniline in aqueous solution due to the hydrophobic nature of the films. However with PTFA films the neutral to polaron transition was observed from 420 to
$730 \mathrm{~nm}$, while the neutral transition was moved to lower wavelengths. A low colouration efficiency of $36.6 \mathrm{~cm}^{2} \mathrm{C}^{-1}$ was observed while PTFA polymer exhibited a contrast change of orange to a more transparent orange.

\section{Acknowledgements}

This work was performed with the support of the joint University of Limerick and Dublin Institute of Technology Common Interest Group and the Programme for Research in Third Level Institutions (INSPIRE). The assistance of Dr. C. Dickinson and A. Singh in SEM analysis is acknowledged. We would like to thank the reviewers for their helpful comments.

\section{References}

[1] J. Heinze, in: H. Lund, O. Hammerich (Eds.), Electrochemistry of Conducting Polymers in Organic Electrochemistry, Marcel Dekker, New York, Basel, 1991.

[2] T.A. Skotheim, R.L. Elsenbaumer, J.R. Reynolds (Eds.), Handbook of Conducting Polymers, 2nd edition, Marcel Dekker, New York, 1998.

[3] P.M.S. Monk, D.R. Rosseinsky, Electrochromism: Fundamentals and Applications, Cambridge University Press, New York, 1995.

[4] R.J. Mortimer, A.L. Dyer, J.R. Reynolds, Displays 27 (2006) 2.

[5] K. Aydemir, S. Tarkuc, A. Durmus, G.E. Gunbas, L. Toppare, Polymer 49 (2008) 2029.

[6] R.J. Mortimer, Chemical Society Reviews 26 (1997) 147.

[7] M. Freund, B. Deore, Self-doped Conducting Polymers, John Wiley \& Sons Ltd., Chichester, UK, 2007.

[8] J. Niessen, U. Schroder, M. Rosenbaum, F. Scholz, Electrochemistry Communications 6 (2004) 571

[9] A.H. Kwon, J.A. Conklin, M. Makhinson, R.B. Kaner, Synthetic Metals 84 (1997) 95.

[10] A. Cihaner, A.M. Onal, Polymer International 51 (2002) 680.

[11] J. Zhang, L. Gao, J. Sun, Y. Liu, Y. Wang, J. Wang, Diamond and Related Materials $22(2012) 82$.

[12] M.L. Machala, L. Muller-Meskamp, S. Gang, S. Olthof, K. Leo, Organic Electronics 12 (2011) 1518.

[13] S.A. Mauger, A.J. Moule, Organic Electronics 12 (2011) 1948.

[14] A.J.C. da Silva, F.A. Ribeiro Nogueira, J. Tonholo, A.S. Ribeiro, Solar Energy Materials and Solar Cells 95 (2011) 2255.

[15] S. Vogel, R. Holze, Electrochimica Acta 50 (2005) 1587.

[16] S. Little, S.F. Ralph, C.O. Too, G.G. Wallace, Synthetic Metals 159 (2009) 1950.

[17] N. Sato, T. Nonaka, Nippon Kagaku Kaishi (1997) 451.

[18] M. Grzeszczuk, A. Kepas, G. Zabinska-Olszak, Electrochimica Acta 49 (2004) 2405.

[19] A. Lima, P. Schottland, S. Sadki, C. Chevrot, Synthetic Metals 93 (1998) 33.

[20] B. Garcia, D. Bélanger, Synthetic Metals 98 (1998) 135.

[21] V. Eric, D.A. Anslyn, Dougherty, Modern Physical Organic Chemistry, 2006

[22] A.J. Bard, L.R. Faulkner, Electrochemical Methods: Fundamentals and Applications, 2nd edition, Wiley, New York, 2001.

[23] M. Gao, Y. Yang, M. Diao, S.G. Wang, X.-h. Wang, G. Zhang, G. Zhang, Electrochimica Acta 56 (2011) 7644.

[24] J. Arjomandi, R. Holze, Central European Journal of Chemistry 6 (2008) 199.

[25] A.V. Rosario, E.D. Rios, A.F. Nogueira, L. Micaroni, Solar Energy Materials and Solar Cells 94 (2010) 1338.

[26] D.M.Welsh, A. Kumar, E.W. Meijer, J.R. Reynolds, Advanced Materials 11 (1999) 1379.

[27] L. Ma, Y. Li, X. Yu, Q. Yang, C.-H. Noh, Solar Energy Materials and Solar Cells 93 (2009) 564.

[28] J.S. Zhao, B. Wang, C.S. Cui, R.M. Liu, J.F. Liu, H.S. Wang, H.T. Liu, Electrochimica Acta 56 (2011) 4819.

[29] C.-W. Hu, K.-M. Lee, K.-C. Chen, L.-C. Chang, K.-Y. Shen, S.-C. Lai, T.-H. Kuo, C.-Y Hsu, L.-M. Huang, R. Vittal, K.-C. Ho, Solar Energy Materials and Solar Cells 99 (2012) 135.

[30] B. Sarı, M. Talu, Synthetic Metals 94 (1998) 221. 